\title{
Chiral Ferrocenyl Phosphine-Triazines as Ligands for Asymmetric Allylic Substitution
}

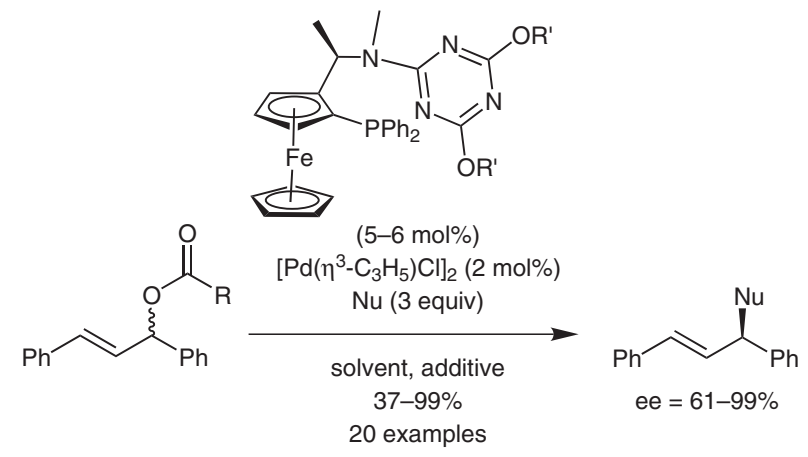

Metal-Catalyzed

Asymmetric

Synthesis and

Stereoselective

Reactions

Key Words

palladium(II)

allylic alkylation

allylic amination

triazines

ligands

Significance: Asymmetric allylic alkylations have been exhaustively studied, and excellent enantioselectivities have been demonstrated in numerous cases. Ferrocenyl-based P,N-ligands have recently received attention, with the incorporation of $\mathrm{N}$ heterocycles believed to influence selectivity. The pendant triazine was found to increase enantioselectivity, with better selectivity than cases with less $\mathrm{N}$ content. Allylic substitution with malonates ( $\alpha$-substituted and unsubstituted) and benzylamine were demonstrated, displaying excellent yield and selectivity with malonates, and good yield and selectivity with amination.
Comment: The triazine ligand where $R^{\prime}=P h$ showed highest utility, providing the best combination of yield and enantioselectivity. For a similar approach employing $\mathrm{N}$-heteroaryls towards $\mathrm{Rh}$ catalyzed hydroboration, see: D. J. Connolly, P. M. Lacey, M. McCarthy, C. P. Saunders, A.-M. Carroll, R. Goddard, P. J. Guiry J. Org. Chem. 2004, 69, 6572-6589. 